Sains Malaysiana 48(8)(2019): 1787-1798

http://dx.doi.org/10.17576/jsm-2019-4808-26

\title{
Deep Neural Network for Forecasting Inflow and Outflow in Indonesia
}

(Rangkaian Saraf Dalam untuk Ramalan Aliran Masuk dan Aliran Keluar di Indonesia)

\section{Suhartono, Dimas Ewin Ashari, Dedy Dwi Prastyo, Heri Kuswanto \& MuHAmmad Hisyam LeE*}

\begin{abstract}
An optimal planning in the preparation of Money Requirement Plan (MRP) by Bank Indonesia is highly beneficial to maintain the availability of money in the community. One of the main factors needed in preparing of MRP is an accurate information about inflow and outflow. This study is to apply Deep Neural Network (DNN) for forecasting inflow and outflow in Indonesia and to compare its performance to ARIMAX as a simpler method and hybrid Singular Spectrum Analysis and DNN (SSA-DNN) as a more complex method. This study focuses on determining the best inputs in DNN, particularly for forecasting time series. A simulation study is used for evaluating the performance of each method related to the patterns in the time series. The real data are monthly inflow and outflow on 5 banknotes denominations from January 2003 to December 2016. The performance was evaluated based on Root Mean Square Error Prediction and Symmetry Mean Absolute Percentage Error Prediction criteria. The results of the simulation study showed that DNN yielded a more accurate forecast than ARIMAX and hybrid SSA-DNN in predicting time series with a trend, seasonal, calendar variation, and nonlinear noise patterns. Moreover, the results of inflow and outflow forecasting showed that DNN provided a more accurate prediction on most all banknotes denominations compared to ARIMAX and hybrid SSA-DNN. In general, these results show that DNN as machine learning model outperforms both ARIMAX as a simpler statistical model and hybrid SSA-DNN as a more complex model.
\end{abstract}

Keywords: ARIMAX; DNN; inflow and outflow; SSA-DNN; time series forecasting

\section{ABSTRAK}

Suatu perancangan yang optimum dalam penyediaan Pelan Wang Keperluan (MRP) oleh Bank Indonesia sangat berfaedah untuk mengekalkan kewujudan wang dalam masyarakat. Salah satu faktor utama yang diperlukan dalam menyediakan MRP adalah maklumat yang tepat tentang aliran masuk dan aliran keluar. Kajian ini bertujuan untuk menerapkan Rangkaian Neural Dalam (DNN) untuk ramalan aliran masuk dan aliran keluar di Indonesia dan untuk membandingkan prestasi ARIMAX sebagai kaedah yang mudah dan hibrid Analisis Spektrum Singular dan DNN (SSA-DNN) sebagai satu kaedah yang lebih kompleks. Kajian ini tertumpu kepada menentukan input terbaik DNN, terutamanya bagi peramalan siri masa. Kajian simulasi yang digunakan untuk menilai prestasi setiap kaedah yang berkaitan dengan corak dalam siri masa. Data sebenar adalah aliran masuk dan aliran keluar bulanan pada 5 denominasi wang kertas dari Januari 2003 untuk Disember 2016. Prestasi dinilai berdasarkan ramalan punca min ralat kuasa dua dan ramalan simetri min mutlak peratusan ralat. Keputusan bagi kajian simulasi menunjukkan bahawa DNN menghasilkan ramalan yang lebih tepat berbanding ARIMAX dan hibrid SSA-DNN untuk meramalkan siri masa dengan kecenderungan, bermusim, perubahan kalendar dan corak bunyi tak linear. Selain itu, keputusan ramalan aliran masuk dan aliran keluar menunjukkan bahawa DNN membuat ramalan yang lebih tepat bagi kebanyakan denominasi wang kertas berbanding ARIMAX dan hibrid SSA-DNN. Secara amnya, keputusan ini menunjukkan bahawa DNN sebagai model pembelajaran mesin yang lebih baik berbanding ARIMAX sebagai model statistik mudah dan hibrid SSA-DNN sebagai model yang lebih kompleks.

Kata kunci: Aliran masuk dan aliran keluar; ARIMAX; DNN; SSA-DNN; waktu ramalan siri

\section{INTRODUCTION}

The main considerations of Bank Indonesia (BI) in the making of the Money Requirement Plan (MRP) are the inflow and outflow, the available cash positions, the amount of money destroyed, the availability of minimum cash, also economic and geographic conditions in Indonesia (Bank Indonesia 2011). Hence, an accurate prediction of money demands in each denomination is very useful in preparing of MRP. In general, the fluctuation of inflow and outflow in Indonesia contains trend, seasonal, and calendar variation patterns due to some holidays and festivals that be celebrated by the community. Hence, decomposition methods can be applied for evaluating these patterns separately. Decomposition of patterns in time series data into trend, seasonality and noise components can improve the process of time series analysis in constructing better prediction (Bowerman 1993).

Many kinds of researches about inflow and outflow forecasting in Indonesia have been done and some methods have been proposed and applied. Initially, 
some classical time series methods such as time series regression, ARIMA and ARIMAX were applied for inflow and outflow forecasting (Setiawan et al. 2015). Then, several researchers used nonlinear and machine learning methods such as Feed-forward Neural Network or FFNN, and hybrid Quantile Regression Neural Network or QRNN (Suhartono et al. 2018a). Recently, a hybrid Singular Spectrum Analysis and Neural Network or SSA-NN also be employed for inflow and outflow forecasting in Indonesia (Suhartono et al. 2017). In general, the main conclusion from these researches was inflow and outflow data in Indonesia consisted of a trend, seasonal, calendar variation, and nonlinearity patterns.

In the last few years, Deep Neural Network or DNN was widely used to solve forecasting problems (Bai et al. 2016; Busseti 2012; He 2017; Lago et al. 2018). Busseti implemented DNN to forecast power loads and found that DNN produced better results than linear regression and kernel (Busseti 2012). Singular Spectrum Analysis or SSA has also been widely applied as a hybrid method combining with various other methods, especially NN. Previous studies about hybrid SSA-NN have concluded that SSA was able to significantly improve the performance of hybrid models (Alzahrani et al. 2017; Kumar \& Jain 2010; Liu et al. 2018; Vautrad \& Ghil 1989; Yu et al. 2017; Zhang et al. 2017).

Due to the nonlinear pattern on inflow and outflow data in Indonesia, this research focuses on the development of DNN for forecasting inflow and outflow in Indonesia. Moreover, one of the main issues that be studied further is how to determine the best architecture of DNN, particularly to identify the best inputs. Most of the previous researches used one hidden layer NN, whereas DNN in this study is the NN with two hidden layers. Furthermore, the performance of DNN will be compared to ARIMAX as a simpler method and hybrid SSA-DNN as a more complex method. The goodness of these methods was evaluated based on Root Mean Square Error Prediction (RMSEP) and Symmetry Mean Absolute Percentage Error Prediction (SMAPEP) criteria.

This paper is organized as follows: Next section reviews the methods, ARIMAX, SSA, DNN, and hybrid SSADNN as forecasting method; Next, we present the results and discussion; and last section presents the conclusion from this study.

\section{MATERIALS AND METHODS}

\section{ARIMAX}

ARIMAX is an extension of the ARIMA model by involving exogenous variables. In this research, these exogenous variables are dummy variables of a trends, seasonal, and calendar variations patterns. In general, the ARIMAX model with $t, D_{i, t}$, and $V_{j, t}$ are dummy variables of trend, seasonal, and calendar variation, respectively, can be written as Ahmad et al. (2015)

$$
Y_{t}=\delta_{1} t+\sum_{i=1}^{s} D_{i, t}+\sum_{j=1}^{c} V_{j, t}+\frac{\theta_{q}(B)}{\phi_{p}(B)} a_{t}
$$

where $\phi_{p}(B)=\left(1-\phi_{1} B-\phi_{2} B^{2}-\ldots-\phi_{p} B^{p}\right), \theta_{p}(B)=(1$ $\left.-\theta_{1} B-\theta_{2} B^{2}-\ldots-\theta_{q} B^{q}\right)$, and $a_{t}$ is residual of ARIMAX model at time t.

\section{SINGULAR SPECTRUM ANALYSIS}

SSA is a forecasting method that combines elements of classical forecasting, multivariate statistics, multivariate geometry, dynamic systems, and signal processing. The main objective of the SSA method was to decompose the original time series into several additive components, such as trend, oscillatory, and noise components (Golyandina \& Zhigljavsky 2013). In general, SSA has four main stages, Embedding, Singular Value Decomposition (SVD), Eigentriple Grouping, and Diagonal Averaging.

The procedure in embedding is to map the original time series into a multidimensional sequence of a lagged vector. Let's assume $L$ is an integer number represents window length with $1<L<n$, the formation of lagged vectors where $K=n-L+1$ is $Y_{i}=\left(f_{i}, f_{i+1}, \ldots f_{i+L-1}\right)^{T}, 1 \leq$ $i \leq K$, which has a dimension of $L$. If the dimensions of $Y$ are emphasized, then $Y$ is referred to as $L$-lagged vectors. The path matrix of the $F$ series is illustrated as follows:

$$
\mathbf{Y}=\left[Y_{i}: \ldots: Y_{K}\right]=\left[\begin{array}{ccccc}
f_{1} & f_{2} & f_{3} & \ldots & f_{K} \\
f_{2} & f_{3} & f_{4} & \ldots & f_{K+1} \\
f_{3} & f_{4} & f_{5} & \ldots & f_{K+2} \\
\vdots & \vdots & \vdots & \ddots & \vdots \\
f_{L} & f_{L+1} & f_{L+2} & \cdots & f_{n}
\end{array}\right]
$$

Let $\mathbf{S}=\mathbf{Y} \mathbf{Y}^{\mathbf{T}}$ and $\lambda_{1}, \lambda_{2}, \ldots, \lambda_{L}$ be the eigenvalues of the matrix $\mathbf{S}$ where $\lambda_{1} \geq \lambda_{2} \geq \ldots \geq \lambda_{L} \geq 0$ and $U_{1}, U_{2}, \ldots$, $U_{L}$ are eigenvectors of the matrix $\mathbf{S}$ corresponding to the eigenvalues. Note that $d=\max \{i\}$ so that $\lambda_{i}>0$ is the rank of the matrix $\mathbf{Y}$. If for $S=V_{i}=\mathbf{Y}^{T} U_{i} / \sqrt{\lambda_{i}}$ for $i=1$, $2, \ldots, \mathrm{d}$, then SVD of the path matrix $\mathbf{Y}$ can be written as $\mathbf{Y}=\mathbf{Y}_{1}+\mathbf{Y}_{2}+\ldots+\mathbf{Y}_{\mathrm{d}}$, where $\mathbf{Y}_{\mathrm{i}}=\sqrt{\lambda_{i}} U_{i} V_{i}^{\mathrm{T}}$. Matrix $\mathbf{Y}_{i}$ has rank 1 and often called as an elementary matrix. The $\operatorname{set}\left(\sqrt{\lambda_{i}}, U_{i}, V_{i}\right)$ is called $i$-th eigentriple to SVD.

After the SVD equation is obtained, the grouping procedure will partition the set of indices $\{1,2, \ldots, d\}$ into $\mathrm{m}$ subsets of mutually independent, $I_{1}, I_{2}, \ldots, I_{m}$. Let $I=\left\{i_{1}, i_{2}, \ldots, i_{p}\right\}$, the resulting $\mathbf{Y}_{\mathrm{i}}$ matrix corresponds to group $I$ defined as a matrix with $\mathbf{Y}_{I}=\mathbf{Y}_{i_{1}}+\mathbf{Y}_{i_{2}}+\ldots+\mathbf{Y}_{i_{p}}$. This matrix is calculated for groups and this step will lead to decomposition form, i.e. $\mathbf{Y}=\mathbf{Y}_{I_{1}}+\mathbf{Y}_{I_{2}}+\ldots+\mathbf{Y}_{I_{m}}$. Set $m$ selection procedures, $I_{1}, I_{2}, \ldots, I_{m}$ are called eigentriple groupings. If $m=d$ and $I_{j}=\{j\}, j=1,2, \ldots, d$, then the corresponding grouping is called elementary. 
Let $\mathbf{Z}$ be $L \times K$ matrix with element $z_{i j}, 1 \leq i \leq L, 1 \leq j$ $\leq K$ for $L \leq K$. Let's assume the values of $L^{*}=\min \{L, K\}$, $K^{*}=\max \{L, K\}$, and $n=L-K-1$. If $L<K$ then $z_{i j}^{*}=z_{i j}$, and if $L>K$ then $z_{i j}^{*}=z_{i j}$. Diagonal averaging moves the $Z$ matrix to the series $g_{1}, g_{2}, \ldots, g_{n}$ by following formula:

$$
g_{k}=\left\{\begin{array}{cl}
\frac{1}{k} \sum_{m=1}^{k} z_{m, k-m+1}^{*} & \text { for } 1 \leq k<L^{*} \\
\frac{1}{L^{*}} \sum_{m=1}^{L^{*}} z_{m, k-m+1}^{*} & \text { for } L^{*} \leq k<K^{*} \\
\frac{1}{n-k+1} \sum_{m=k-K^{*}+1}^{n-K^{*}+1} z_{m, k-m+1}^{*} & \text { for } K^{*} \leq k<n
\end{array}\right.
$$

This equation corresponds to the average matrix element over the 'antidiagonals', $i+j=k+1$. If the averaging diagonal is applied to the matrix $\mathbf{Y}_{I_{k}}$, then this process will obtain a reconstructed series $F^{(k)}=\left(f_{1}^{(k)}, f_{1}^{(k)}, \ldots\right.$, $\left.f_{1}^{(k)}\right)$. Therefore, the initial series $f_{1}, f_{2}, \ldots, f_{n}$ are decomposed into a sum of the reconstructed series, i.e. $f_{j}=\sum_{k=1}^{m} f_{j}^{(k)}, j=$ $1,2, \ldots, n$.

\section{DEEP NEURAL NETWORK}

Deep learning (DL) was initially proposed in the field of computer science for identification and recognition of images, sounds and translator machines. Furthermore, DL is widely used for wind speed and electrical load forecasting. It is also developed simultaneously with other methods such as quantile regression, feature selection, multi-model framework, an ensemble model. Recently, DL is used in various applied fields of science. The basic of DL model is Deep Neural Network or DNN, i.e. a natural extension of traditional multi-layer perceptrons (MLPs) that use many hidden layers. The commonly used standard activation function is the sigmoid function (Lago et al. 2018).

Deep feedforward networks which are called feedforward neural networks (FFNN) or multi-layers perceptrons (MLPS) are classic deep-learning models.
The purpose of an FFNN is to estimate some functions $f^{*}$ (Goodfellow et al. 2016). In forecasting, the widely used neural network method is FFNN. In FFNN, the process begins with inputs received by neurons, where these neurons are grouped in layers. Information received from the input layer proceeds to the layers in the FFNN sequentially to reach the output layer. The layers between input and output are called hidden layers (Suhartono 2007). One of the input selection strategy in FFNN for time series forecasting is based on the significant lags of the Partial Autocorrelation Function (PACF) of stationary data (Crone \& Kourentzes 2009). The DNN model can be generalized from FFNN with one hidden layer into two hidden layers as in Figure 1.

Furthermore, the calculation of output values $\hat{y}$ of DNN can be generalized from one-layer FFNN as follows:

$$
\hat{y}_{k}=f^{o}\left[\sum_{l=1}^{r}\left[w_{l}^{o} f_{l}^{h_{2}}\left(\sum_{j=1}^{q} w_{l j}^{h_{2}} f_{j}^{h_{1}}\left(\sum_{i=1}^{p} w_{j i}^{h_{1}} x_{i(k)}+b_{j}^{h_{1}}\right)+b_{l}^{h_{2}}\right)+b^{o}\right]\right]
$$

where $x_{i(k)}$ is input variables $(i=1,2, \ldots, p ; k=1,2, \ldots, n)$, $\hat{y}_{(k)}$ is fits value of output variable, $k$ is index pairing input and output variable $\left(x_{i(k)}, \hat{y}_{(k)}\right), w_{j i}^{h_{1}}$ is weight of the $i$-th input that leads to the $j$-th neuron in first hidden layer $j=1,2$, $\ldots, q, b_{j i}^{h_{1}}$ is bias in the $j$-th neuron in first hidden layer, $f_{j}^{h_{1}}$ is activation function at the $j$-th neuron in first hidden layer, $w_{l}^{o}$ is weight of the $l$-th neuron from the second hidden layer that leads to the output layer, $b^{o}$ is bias at the neuron in output layer, $f^{\circ}$ is an activation function at the neuron in output layer, $w_{l j}^{h_{2}}$ is weight of the $j$-th neuron in first hidden layer that leads to the 1 -th neuron in second hidden layer $(l$ $=1,2, \ldots, r), b_{l}^{h_{2}}$ is bias at the $l$-th neuron in second hidden layer, and $f_{l}^{h_{2}}$ is an activation function at the $l$-th neuron in second hidden layer. In this study, the activation function used in the hidden and output layer are standard sigmoid function and a linear function, respectively. The sigmoid function is considered quite simple and widely used in many kinds of researches (Lago et al. 2018).

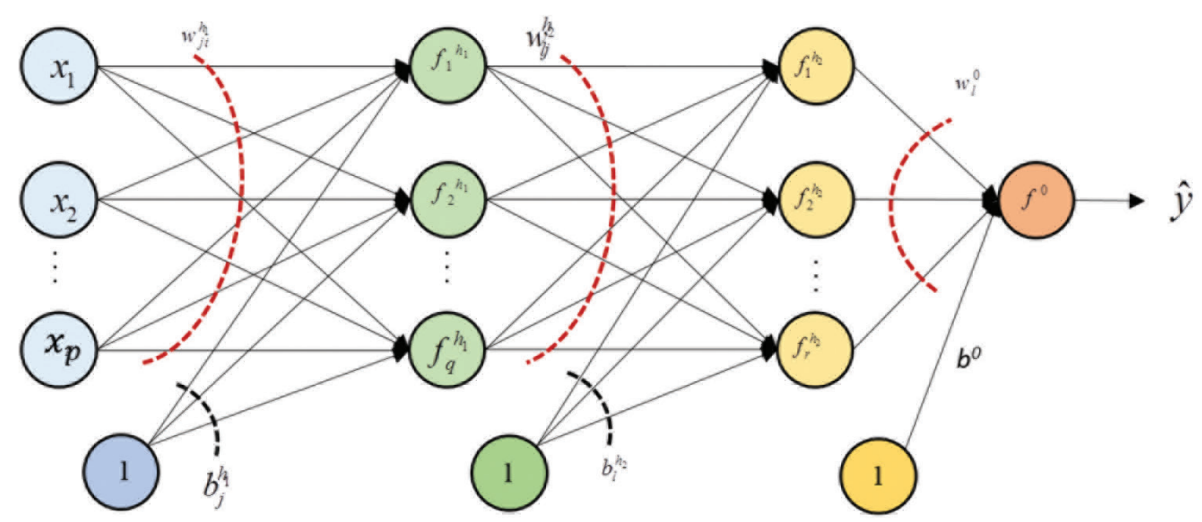

Input layer hidden layer 1

hidden layer 2 output layer

FIGURE 1. Deep Neural Networks architecture 
The following steps are the proposed procedure of DNN model for time series forecasting application.

Divide data into two parts, training and testing dataset; Perform preprocessing of actual data by using a standardized method; Determine the inputs of DNN. In this study, the inputs are dummy variables of trend, seasonal, calendar variation, and lags of $\mathrm{Y}_{\mathrm{t}}$. The selection of lags input is determined in two schemes: i.e. Based on the significant PACF lags from the original data (Gorr 1994). The model is written as DNN-1, Use Autoregressive (AR) order of the ARIMAX model. If the ARIMAX model does not have an AR order or $\mathrm{p}=$ 0 then the inputs are determined based on significant PACF lags of the noise of ARIMAX (Crone \& Kourentzes 2009). The model is written as DNN-2; and Choose the best number of neurons on each hidden layer based on the smallest Root Mean of Square Error Prediction or RMSEP.

\section{HYBRID SINGULAR SPECTRUM ANALYSIS AND DEEP NEURAL NETWORK (SSA-DNN)}

Zubaidi et al. (2018) used SSA as an NN preprocessing stage in forecasting monthly water consumption. The hybrid SSA-DNN model in this study consists of two levels of modelling. The first is modelling separately of trend and seasonal components of SSA decomposition by using polynomial and dummy regression, respectively. Then, the residuals of these both regression and the noise component of SSA decomposition are summed to be one series. Finally, this series is modelled by DNN in the second level as in Figure 2.

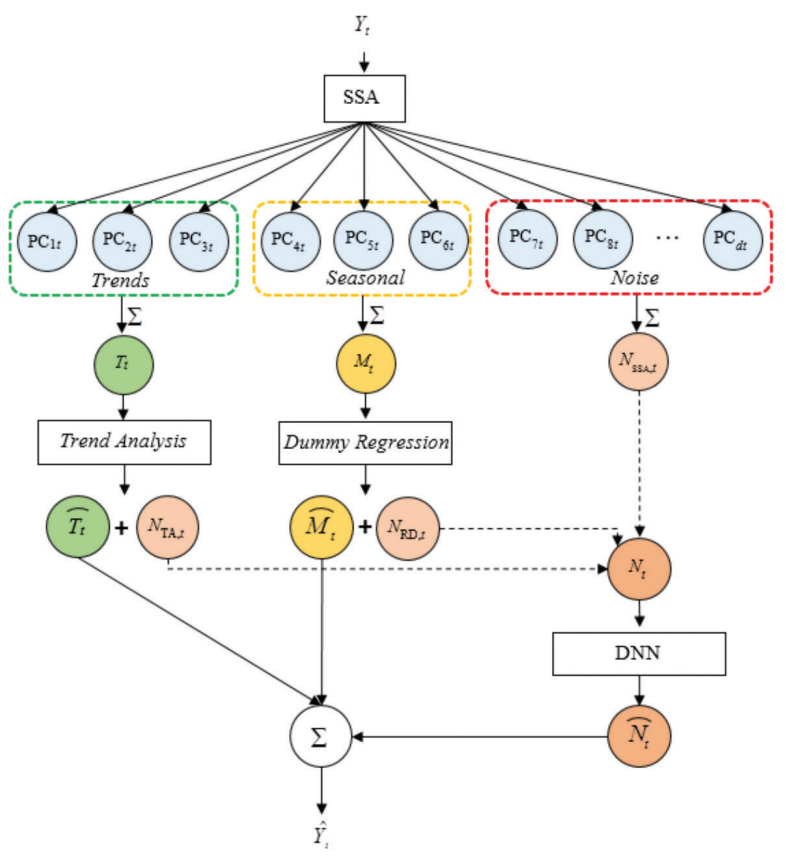

FIGURE 2. Forecasting procedure of the hybrid SSA-DNN Model
In general, the proposed hybrid SSA-DNN has the following steps of modeling. Apply SSA decomposition to obtain trend, seasonal and noise components; Employ polynomial regression for trend component of SSA; Employ dummy regression for the seasonal component of SSA; Aggregate the noise component of SSA and both residuals of trend and seasonal regression at step 2 and 3 by summing all these series; Apply DNN as time series method for forecasting this aggregate series. The lag inputs are determined based on the significant lags of PACF as proposed by Crone and Kourentzes (Crone \& Kourentzes 2009); Obtain the fits and forecasts of hybrid SSA-DNN by summing the fits and forecasts from the polynomial regression, dummy regression, and DNN, respectively.

\section{ACCURACY CRITERIA}

Cross-validation principle which focuses only on the forecast results for the testing dataset is used for selecting the best model (Chen \& Yang 2004). The criteria for model evaluation are RMSEP and SMAPEP which shown in the following equation, where $\mathrm{C}$ is the forecast period:

$$
\begin{aligned}
& \text { RMSEP }=\sqrt{\frac{1}{C} \sum_{l=1}^{C}\left(Y_{n+1}-\hat{Y}_{n}(1)\right)^{2}} \\
& \text { SMAPEP }=\left(\frac{1}{C} \sum_{l=1}^{C} \frac{2\left|Y_{n+1}-\hat{Y}_{n}(l)\right|}{\left(\left|Y_{n+1}\right|+\left|\hat{Y}_{n}(l)\right|\right.}\right) \times 100 .
\end{aligned}
$$

\section{INFLOW AND OUTFLOW DATA}

Outflow transactions represent information concerning the flow of banknotes and coins issued by Bank Indonesia to banks and the public. It is consisting of withdrawal from commercial banks, non-bank withdrawals, cash in exchange for redemption, withdrawal in the form of cash deposits in general banks, and other withdrawals. Meanwhile, rupiah deposit transactions (inflow) constitute information concerning the flow of banknotes and coins coming from banks and the public to Bank Indonesia. It is consisting of deposits of commercial banks, non-bank deposits, cash transfers in the framework of the proceeds of exchange, deposits in the framework of cash entries in commercial banks, and other deposits (Bank Indonesia 2018).

\section{RESULTS AND DISCUSSION}

\section{SIMULATION STUDY}

A simulation study was conducted to evaluate the performance of ARIMAX, DNN and SSA-DNN in handling trend, seasonal, calendar variation and noise patterns. Data were generated for each component of trend, seasonal, calendar variation patterns as well as linear (for scenario 1 ) and nonlinear noise (for scenario 2) pattern as follows:

$$
Y_{t}=T_{t}+S_{t}+V_{t}+N_{t}
$$


where

$T_{t}$ is the $0.1 t$

$M_{t}$ is the $20 M_{1, t}+23 M_{2, t}+23 M_{4, t}+20 M_{5, t}+15 M_{6, t}+$ $10 M_{7, t}+7 M_{8, t}+5 M_{9, t}+7 M_{10, t}+10 M_{11, t}+15 M_{12, t} ;$ and

$V_{t}$ is the $23 V_{1, t}+37 V_{2, t}+44 V_{3, t}+48 V_{4, t}+56 V_{1, t+1}$ $+34 V_{3, t+1}+30 V_{4, t+1}$

$N_{t}$ consist of two types, i.e. (1) Linear noise: $N_{1, t}=$ $0.45 N_{1, t}+a_{t}$, and (2) Nonlinear noise that follows $\operatorname{ESTAR}(1): N_{2, t}=6.5 N_{2, t-1} \cdot \exp \left(-0.25 N_{t-1}^{2}\right)+a_{t}$, where $a_{t} \sim \operatorname{IIDN}(0.1)$.

Both scenarios are used to evaluate the performance of ARIMAX, DNN and SSA-DNN methods in handling all aforementioned patterns, particularly calendar variation effect. The time series plot of these simulation data is shown in Figure 3.

Each scenario has been replicated 5 times which is distinguished by the linear and nonlinear of the noise component. Simulation data were analyzed using ARIMAX, DNN and SSA-DNN methods. After obtaining the best model for each method, the forecast accuracy comparison is done based on the RMSEP and SMAPEP criteria to determine the best method.

The results of the testing dataset show that the best model for forecasting data in scenario 1 and 2 are ARIMAX and DNN, respectively. It is shown by the smallest value of RSMEP and SMAPEP of ARIMAX at scenario 1 and DNN at scenario 2 in most replication. Moreover, the results also indicate overfitting problem in SSA-DNN at scenario 2, high accurate forecast only at training dataset and poor forecast at the testing part. Additionally, the RMSEP ratios of DNN-1, DNN-2 and SSA-DNN against ARIMAX are shown in Table 1. The ratio less than one indicates that the method yields more accurate prediction than ARIMA.

In general, DNN with the lag inputs as the AR order of noise component (DNN-2) performs better prediction than others. Thus, the results show two important conclusions, DNN as a complex model yields better forecast than ARIMAX as a simpler one, and Hybrid SSA-DNN as a complex model not yield better forecast than DNN as a simpler one. These results in line with the first result of $\mathrm{M} 3$ competition, but not consistent with the third result (Makridakis \& Hibon 2000).

\section{INFLOW AND OUTFLOW DATA IN INDONESIA}

There are 14 series data of inflow and outflow. These data are monthly from January 2003 to December 2016. For modelling purpose, the data are divided into two parts, i.e. training and testing dataset for data in 2003-2015 and 2016, respectively. The variables are for represent as outflow series denominations of Rp100,000.00, Rp50,000.00, Rp20,000.00, Rp10,000.00, Rp5,000.00, Rp2,000.00, and $\mathrm{Rp} 1,000.00$, respectively, and for represent as inflow series denominations of Rp100,000.00, Rp50,000.00, Rp20,000.00,Rp10,000.00, Rp5,000.00, Rp2,000.00, and Rp1,000.00, respectively. Some dummy variables are used to reconstruct the data patterns, i.e. trend, seasonal, and
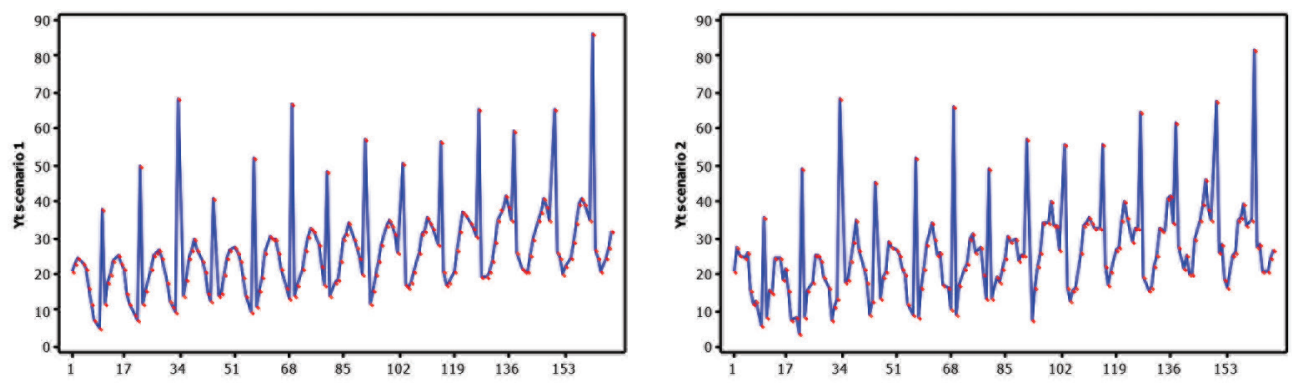

FIGURE 3. Time series plot of the scenario 1 and 2 of simulation data

TABLE 1. Ratio of RMSEP between DNN and SSA-DNN to ARIMAX

\begin{tabular}{cccccccc}
\hline \multirow{2}{*}{$\begin{array}{c}\text { Data } \\
\text { scenario }\end{array}$} & Replication & \multicolumn{3}{c}{ RMSEP } & \multicolumn{3}{c}{ sMAPEP } \\
\cline { 3 - 8 } & & DNN-1 & DNN-2 & SSA-DNN & DNN-1 & DNN-2 & SSA-DNN \\
\hline \multirow{2}{*}{1} & 1 & 1.39 & 0.93 & 1.64 & 1.31 & 1.04 & 2.32 \\
& 2 & 1.20 & 2.92 & 1.45 & 1.16 & 2.13 & 1.52 \\
& 3 & 1.11 & 0.73 & 0.91 & 1.16 & 0.69 & 0.93 \\
& 4 & 1.88 & 1.55 & 1.38 & 1.67 & 1.29 & 1.01 \\
& 5 & 2.25 & 1.76 & 1.68 & 1.38 & 1.70 & 1.63 \\
\hline \multirow{2}{*}{2} & 1 & 0.81 & 0.90 & 0.92 & 0.99 & 1.07 & 1.07 \\
& 2 & 1.01 & 0.82 & 0.71 & 0.97 & 0.69 & 0.62 \\
& 3 & 0.95 & 0.87 & 0.94 & 0.95 & 0.91 & 1.06 \\
& 4 & 0.87 & 0.82 & 0.90 & 0.91 & 0.80 & 0.96 \\
& 5 & 0.91 & 0.82 & 0.89 & 1.02 & 0.88 & 0.89 \\
\hline
\end{tabular}


calendar variations. Based on the previous researches, it is known that the dummy variables for calendar variation at outflow are and, whereas at inflow are and . It explains that outflow increases significantly on the month of Eid ul-Fitr and beforehand, while inflow increases on the month of Eid ul-Fitr and thereafter (Suhartono et al. 2018b, 2017).
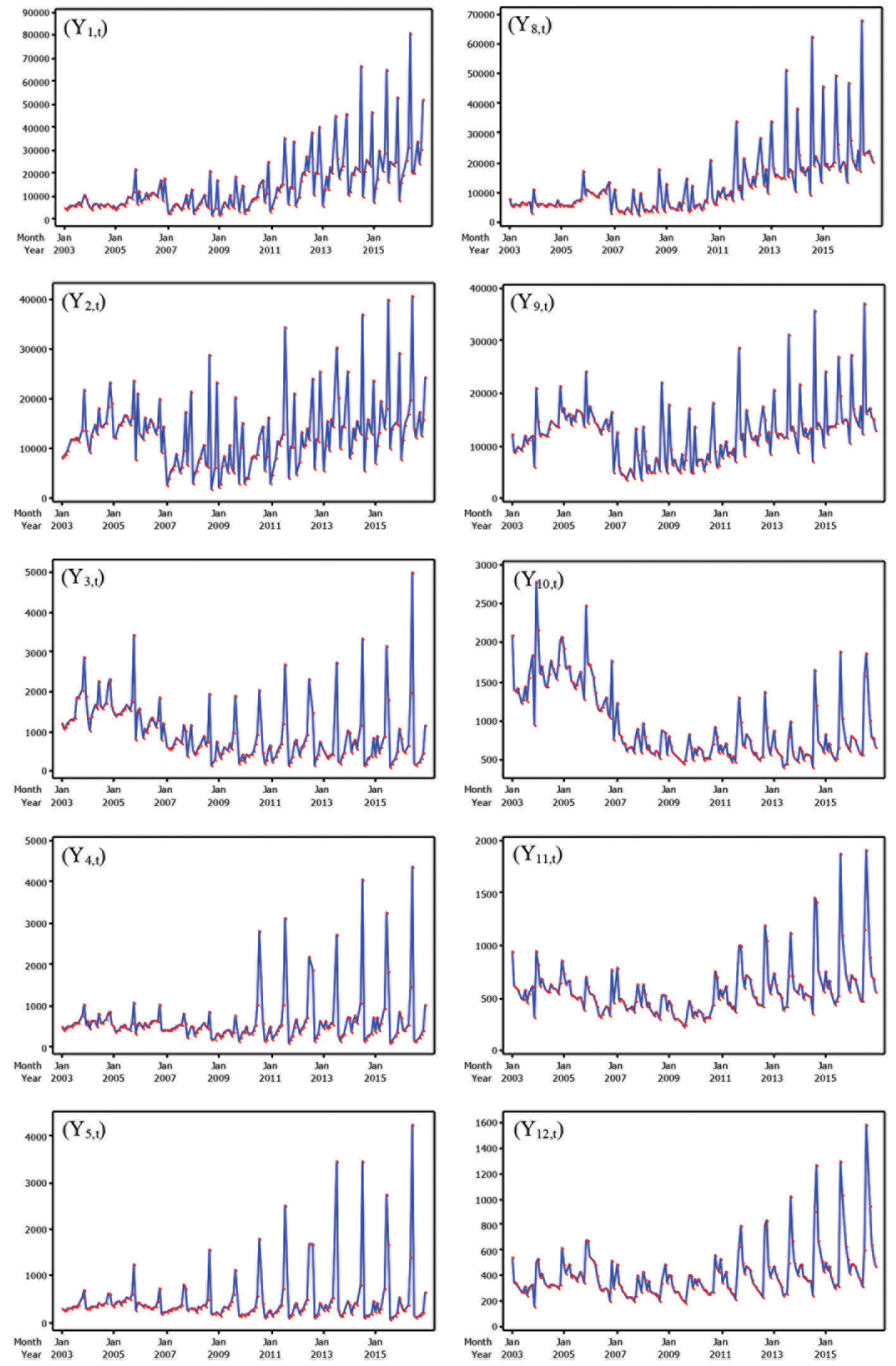

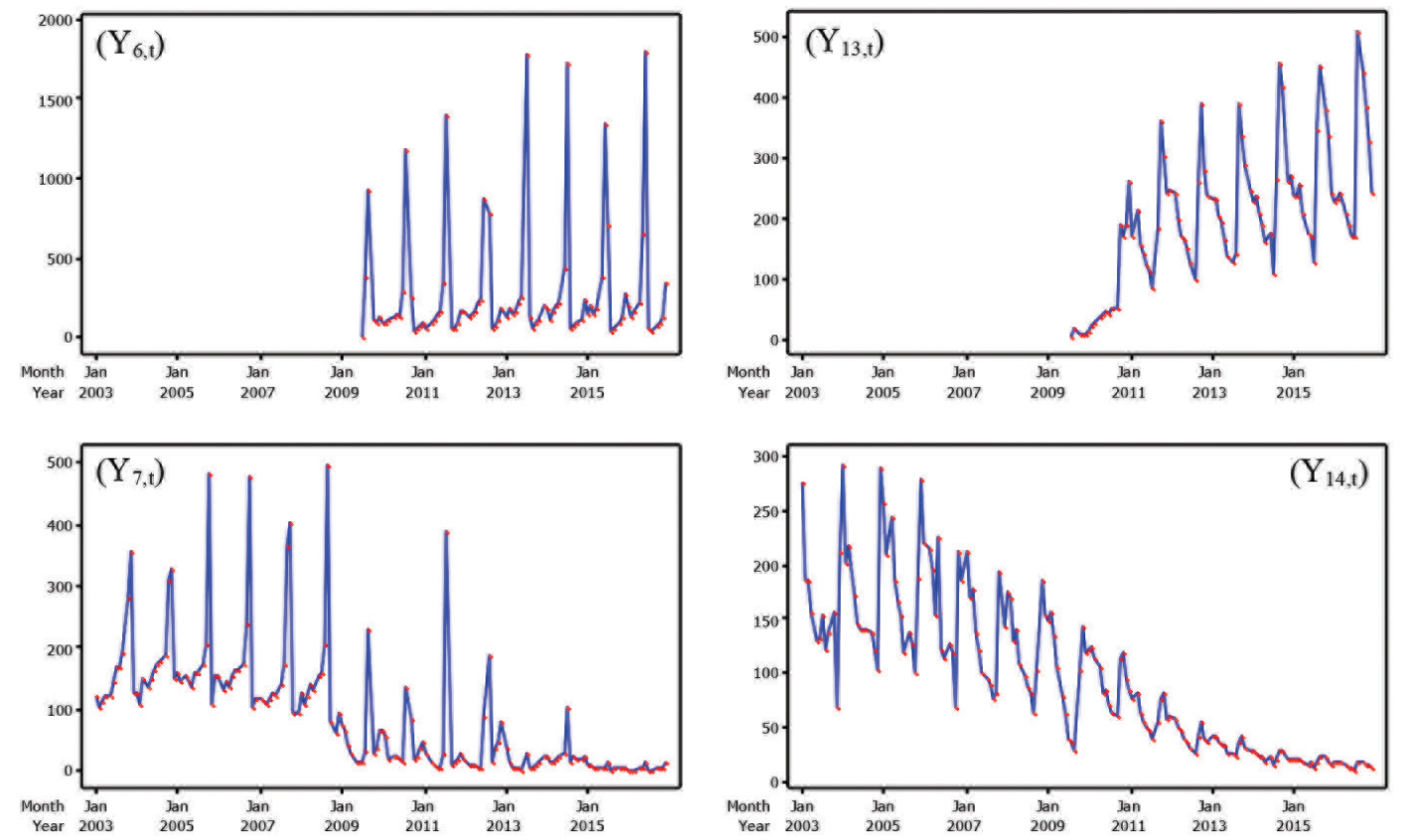

FIGURE 4. Time series plot of total monthly inflow and outflow in Indonesia

The time series plot of monthly inflow and outflow in Indonesia is shown in Figure 4. These graphs show that outflow and inflow increased significantly during the month when Eid ul-Fitr occurred. Additionally, another increasing period of outflow and inflow are one month before and after Eid ul-Fitr, respectively. Moreover, the graphs also show that the trend pattern of outflow and inflow change to slightly decrease in the period 2007 to 2010 . It was caused by the new policy of Bank Indonesia about limitation for a cash deposit for not feasible money. Therefore, this policy becomes an intervention and included in the analysis as additional dummy variables, i.e. for period 2017 to 2010 , and for period 2011 onwards.

\section{ARIMAX FOR FORECASTING INFLOW AND OUTFLOW IN INDONESIA}

There are two conditional steps for modelling inflow and outflow using the ARIMAX method. The first is to apply Time Series Regression or TSR with predictors are for trend, for dummy about policy, for monthly seasonal dummy, and for calendar variation. If the residuals of TSR satisfy white noise assumption, then the modeling process is finished and TSR is chosen as the best model. Otherwise, the ARIMA model is used for modelling the residual of TSR to build ARIMAX model. The results of the ARIMAX modelling for all denominations of inflow and outflow are shown in Table 2.

TABLE 2. The best ARIMAX model for each denomination currency

\begin{tabular}{clcc}
\hline \multirow{2}{*}{ Series } & Model & \multicolumn{2}{c}{ Residual } \\
\cline { 3 - 4 } & & White noise & Normal distribution \\
\hline$Y_{1, t}$ & ARIMAX $([10,12], 0,[2])$ & Yes & Yes \\
$Y_{2, t}$ & ARIMAX $([12,13,23,26], 0,0)$ & Yes & Yes \\
$Y_{3, t}$ & TSR & Yes & No \\
$Y_{4, t}$ & TSR & Yes & No \\
$Y_{5, t}$ & ARIMAX $([1,12,23], 0,0)$ & Yes & No \\
$Y_{6, t}$ & TSR & Yes & No \\
$Y_{7, t}$ & ARIMAX $([1,11,13], 0,0)$ & Yes & No \\
\hline$Y_{8, t}$ & ARIMAX $(0,0,[1,12])$ & Yes & No \\
$Y_{9, t}$ & ARIMAX $(0,0,[16,18,24,25])$ & Yes & No \\
$Y_{10, t}$ & ARIMAX $([1,2,6], 0,[3,11,12,20])$ & Yes & No \\
$Y_{11, t}$ & ARIMAX $(1,0,[1,11,12,23])$ & Yes & No \\
$Y_{12, t}$ & ARIMAX $([1,11,12,13], 0,0)$ & Yes & Yes \\
$Y_{13, t}$ & ARIMAX $([1,14], 0,0)$ & Yes & Yes \\
$Y_{14, t}$ & ARIMAX $([1,7,11], 0,[4,12])$ & Yes & Yes
\end{tabular}




\section{DNN FOR FORECASTING INFLOW AND OUTFLOW IN INDONESIA}

As aforementioned, forecasting by DNN is done through preprocessing of original data, determining lags of as inputs, and determining the optimum number of neurons both at the first and second hidden layer. This study proposes and applies two types of DNN with the inputs are dummy variables as in ARIMAX and the lags of . The first is DNN-1 which the lag inputs are selected based on the significant PACF of the original data, and the second is DNN2 which the lags are determined based on the AR order of ARIMAX model. Finally, the optimum number of neurons at the first and second hidden layer is done by trying the combination of 1 to 10 neurons at each hidden layer. Each combination is replicated 10 times.

As an example, the following is a model building of DNN-1 for forecasting outflow on denomination Rp100,000.00. The PACF from original data shows that the significant lags were $1-5,12-15,17,23$, and 24 . It implies the number of inputs is 38 that consists of lags , and dummy variables of a trend, seasonal, intervention, and calendar variation. Then, determination of the best DNN-1 model is tested by 100 combinations of neurons at the first and second hidden layer. The experiment is run by using library neural.net in $\mathrm{R}$. The results show that the best model is DNN-1 with number of neurons in the first and second hidden layer are 9 and 5, respectively, as shown in Figure 5.

The DNN-1 model in Figure 5 can be written as follows (in standardized preprocessing):

$$
\begin{aligned}
\hat{Y}_{1, t}^{*}= & 0.49-0.22 f_{1}^{h_{2}}(.)+4.67 f_{2}^{h_{2}}(.)- \\
& 0.81 f_{3}^{h_{2}}(.)-2.53 f_{4}^{h_{2}}(.)-1.08 f_{5}^{h_{2}}(.)
\end{aligned}
$$

where the activation functions at the second hidden layer are

$$
\begin{aligned}
& f_{1}^{h_{2}}(.)=\left(1+\exp \left(-\left(0.37+0.90 f_{1}^{h_{1}}(.)-\ldots+1.10 f_{9}^{h_{1}}(.)\right)\right)\right)^{-1} \\
& \vdots \\
& f_{5}^{h_{2}}(.)=\left(1+\exp \left(-\left(0.31+0.35 f_{1}^{h_{1}}(.)-\ldots-27.10 f_{9}^{h_{1}}(.)\right)\right)\right)^{-1}
\end{aligned}
$$

and the activation function at the first hidden layer that consists of 38 inputs are as follows:

$$
\begin{aligned}
& f_{1}^{h_{1}}(.)=\left(1+\exp \left(-\left(0.20+1.22 Y_{1, t-1}^{*}-0.36 Y_{1, t-2}^{*}+\ldots-2.13 V_{4, t}^{*}\right)\right)\right)^{-1} \\
& \vdots \\
& f_{9}^{h_{1}}(.)=\left(1+\exp \left(-\left(0.38-2.51 Y_{1, t-1}^{*}-0.49 Y_{1, t-2}^{*}+\ldots-8.68 V_{4, t}^{*}\right)\right)\right)^{-1} .
\end{aligned}
$$

By using the same procedure, the DNN-1 model is applied for all denominations and followed by DNN-2 using lag inputs based on the AR order of ARIMAX model. Summary of the best model of DNN-1 and DNN-2 for each denomination of inflow and outflow are shown in Table 3. The notations $\mathrm{H}_{1}$ and $\mathrm{H}_{2}$ in this table show the optimum number of neurons on the first and second hidden layer. In general, the results show that the value of RMSEP in each denomination is greater than RMSE. It means that the -step ahead forecasts at testing dataset give less accurate prediction than the 1-step ahead forecasts at training dataset.

\section{SSA-DNN FOR FORECASTING INFLOW AND OUTFLOW IN INDONESIA}

SSA-DNN modelling is performed on each aggregate component. Reconstruction is done by grouping trend-

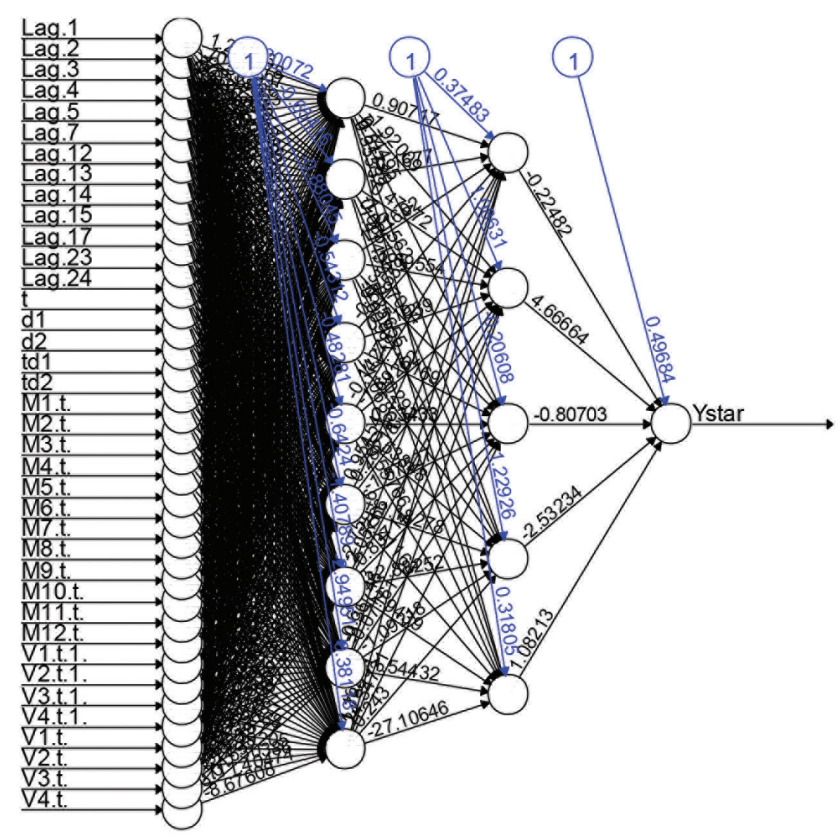

FIGURE 5. Architecture of the best DNN-1 model for forecasting outflow Rp100,000.00 
TABLE 3. The best DNN model for each denominations currency

\begin{tabular}{ccccccccc}
\hline \multirow{3}{*}{ Series } & \multicolumn{3}{c}{ DNN-1 } & & \multicolumn{5}{c}{ DNN-2 } \\
\cline { 2 - 8 } & $\mathrm{H}_{1}$ & $\mathrm{H}_{2}$ & RMSE & RMSEP & $\mathrm{H}_{1}$ & $\mathrm{H}_{2}$ & RMSE & RMSEP \\
\hline$Y_{1, t}$ & 9 & 5 & 217.99 & 4750.18 & 10 & 1 & 478.11 & 4217.85 \\
$Y_{2, t}$ & 7 & 2 & 915.78 & 1915.56 & 10 & 5 & 130.68 & 2242.63 \\
$Y_{3, t}$ & 1 & 2 & 170.39 & 328.98 & 5 & 6 & 95.23 & 391.23 \\
$Y_{4, t}$ & 7 & 7 & 34.98 & 161.22 & 5 & 9 & 58.58 & 152.18 \\
$Y_{5, t}$ & 10 & 2 & 11.92 & 135.25 & 8 & 3 & 25.76 & 178.95 \\
$Y_{6, t}$ & 8 & 8 & 12.82 & 73.44 & 10 & 1 & 16.24 & 46.05 \\
$Y_{7, t}$ & 10 & 8 & 1.45 & 2.96 & 8 & 7 & 2.51 & 3.69 \\
\hline$Y_{8, t}$ & 7 & 10 & 333.22 & 3933.04 & 10 & 5 & 92.79 & 3366.14 \\
$Y_{9, t}$ & 7 & 3 & 264.97 & 1867.02 & 9 & 1 & 274.35 & 1845.9 \\
$Y_{10, t}$ & 6 & 9 & 25.27 & 58.30 & 7 & 10 & 24.24 & 78.53 \\
$Y_{11, t}$ & 2 & 5 & 62.57 & 45.44 & 8 & 6 & 22.4 & 96.47 \\
$Y_{12, t}$ & 5 & 5 & 16.06 & 56.24 & 8 & 10 & 3.76 & 60.65 \\
$Y_{13, t}$ & 10 & 10 & 1.86 & 15.69 & 8 & 1 & 0.72 & 17.21 \\
$Y_{14, t}$ & 10 & 7 & 1.35 & 1.67 & 8 & 10 & 1.01 & 1.71 \\
\hline
\end{tabular}

patterned eigentriples in one trend component and seasonal patterned eigentriples in one seasonal component. Furthermore, the aggregate trend component is modelled by the polynomial regression up to the third order with $t$ as the predictor. Whereas, the aggregate seasonal component is modelled by dummy regression.

The noise component of SSA is identified through slowly decreasing of eigenvalues. Due to eigenvalues slowly decline from the $19^{\text {th }}$ eigenvalue and onwards, then the $1^{\text {st }}$ to $18^{\text {th }}$ eigentriples are grouped into a trend and seasonal components. Identification of trend and seasonal components is done by reconstructing individual eigentriples. It shows that the first component has a trend pattern and the $2^{\text {nd }}$ to $18^{\text {th }}$ components have seasonal patterns. Then, trend and seasonal patterns are modelled by polynomial regression and dummy regression, respectively. The noise component of SSA is summed with residuals of both regressions. The final aggregate noise is modelled by DNN in the scheme of hybrid SSA-DNN. The same model building procedure of DNN in the previous section is employed to this aggregate noise of all denominations of inflow and outflow. The results of hybrid SSA-DNN for each denomination are presented in Table 4.

\section{FORECAST ACCURACY COMPARISON}

Evaluation of forecast accuracy between ARIMAX, DNN and SSA-DNN models are done by using the ratio of RMSE and RMSEP to ARIMAX both in training and testing dataset. It shows that the performance of ARIMAX in forecasting

TABLE 4. The results of SSA-DNN model for each denominations currency

\begin{tabular}{ccccccc}
\hline \multirow{2}{*}{ Series } & \multirow{2}{*}{$\mathrm{H}_{1}$} & \multirow{2}{*}{$\mathrm{H}_{2}$} & \multicolumn{2}{c}{ Training } & \multicolumn{2}{c}{ Testing } \\
\cline { 4 - 7 } & & & RMSE & SMAPE & RMSEP & SMAPEP \\
\hline$Y_{1, t}$ & 10 & 8 & 1383.20 & 4.72 & 10964.71 & 22.59 \\
$Y_{2, t}$ & 9 & 8 & 1653.04 & 7.91 & 4874.09 & 18.34 \\
$Y_{3, t}$ & 8 & 1 & 155.52 & 10.91 & 576.25 & 41.83 \\
$Y_{4, t}$ & 10 & 6 & 105.46 & 10.57 & 502.54 & 40.54 \\
$Y_{5, t}$ & 9 & 10 & 81.09 & 13.36 & 365.52 & 38.24 \\
$Y_{6, t}$ & 6 & 2 & 36.14 & 13.27 & 342.99 & 70.10 \\
$Y_{7, t}$ & 10 & 3 & 9.26 & 5.02 & 56.56 & 162.13 \\
\hline$Y_{8, t}$ & 7 & 4 & 1735.79 & 9.29 & 5048.41 & 13.86 \\
$Y_{9, t}$ & 2 & 8 & 1618.89 & 9.20 & 1795.54 & 9.58 \\
$Y_{10, t}$ & 1 & 10 & 157.94 & 11.44 & 83.73 & 9.42 \\
$Y_{11, t}$ & 7 & 4 & 53.74 & 3.61 & 160.11 & 14.07 \\
$Y_{12, t}$ & 9 & 10 & 36.26 & 5.10 & 76.15 & 9.67 \\
$Y_{13, t}$ & 10 & 8 & 14.80 & 17.34 & 36.16 & 10.40 \\
$Y_{14, t}$ & 9 & 3 & 8.68 & 1.54 & 8.60 & 50.34 \\
\hline
\end{tabular}


outflow and inflow is not as good as DNN or SSA-DNN. Moreover, these results showed that the best model is the DNN method. DNN-1 (red line or bar chart) yields more accurate forecast than other methods in most all denominations of inflow and outflow in Indonesia. Otherwise, the hybrid SSA-DNN model, in general, does not yield a more accurate forecast than simpler models. SSA-DNN outperforms other methods only at inflow denomination of $\operatorname{Rp} 50,000.00$ or $Y_{9, t}$. These results in line with the conclusion of Lago et al. (2018) who compared machine learning and hybrid methods with classical models. Two main results that in line with this previous research are DNN as machine learning model yields more accurate forecast than ARIMAX as a classical statistical model, and SSA-DNN as a hybrid model gives not better results than DNN as a simpler model.

Furthermore, it is well known that the prediction accuracy of the forecasting model may differ depending on the horizon of the forecast period. Therefore, the comparison of forecast accuracy between methods is compared in different length of the forecast horizon, 1-3, 1-6, 1-9, and 1-12 periods. The results are shown at Figure 6.

The results in Figure 6 shows that the DNN-1 and DNN-2 methods yield more accurate forecast than other methods in 13 denominations of inflow and outflow for both short-term ( 3 periods) and long-term (12 periods) forecast horizon. Otherwise, the hybrid SSA-DNN as the most complex model yields the best forecast for inflow denomination of Rp50,000.00 in both short and long-term forecast horizon. In general, the comparison of forecast accuracy between these three methods both in simulation and real data are presented as in Figure 6.

ARIMAX yields more accurate forecast at simulation data with a trend, seasonal, calendar variation, and linear noise components, both in short-term and longterm forecast horizon. Otherwise, DNN becomes the best model for forecasting simulation data with a nonlinear noise component. Moreover, the results on inflow and
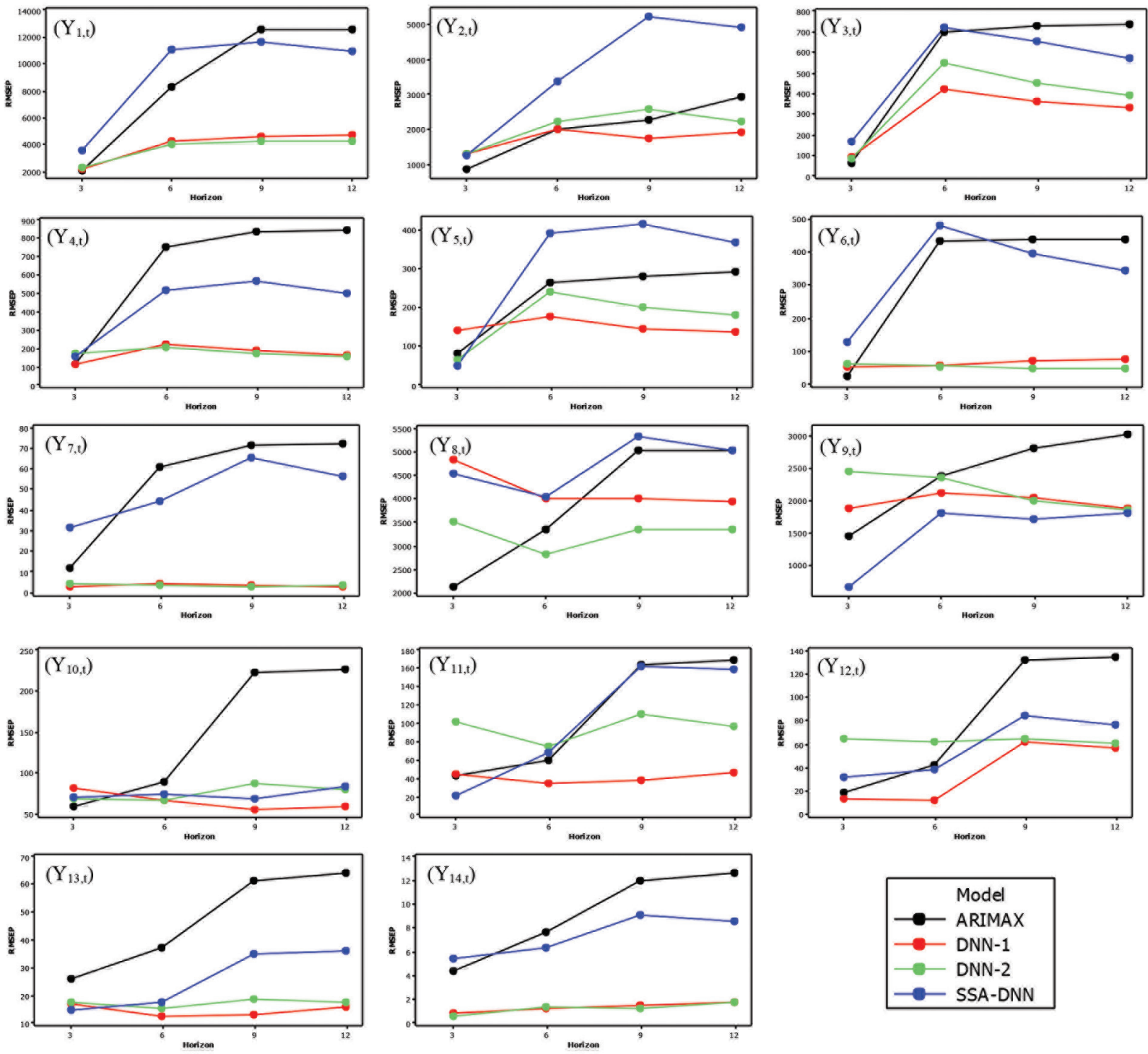

FIGURE 6. The results of RMSEP at all horizon of forecast 
outflow data show that DNN outperforms at 13 out of 14 denominations compared to ARIMAX and hybrid SSADNN, both in short-term and long-term forecast horizon. Specifically, DNN-1 and DNN-2 outperform at 9 and 4 denominations, respectively.

\section{DISCUSSION}

The results of these study could be summarized into two main findings, DNN as machine learning model yields more accurate forecast than ARIMAX as a statistical model, and SSA-DNN as a hybrid model gives not better forecasting results than DNN as a simpler model. The first result has similar conclusion to the research of Lago et al. (2018) and the second result also in line with other previous researches (Alzahrani et al. 2017; Bai et al. 2016; He 2017; Lago et al. 2018). Moreover, the second result not directly supports the conclusion of M3 competition by Makridakis and Hibon (2000) which stated that a hybrid model in average yield better forecast than a simpler one. This conclusion also not in line with the result of M4 competition, i.e. hybrid and combination models tend to give better forecast than machine learning and simple models (Makridakis et al. 2018a, 2018b; Makridakis \& Hibon 2000).

Furthermore, the consistency of the data pattern is suspected to be the cause of the different results of simulation and applied study. In the simulation study, the data pattern over time is the same and repeats consistently. Otherwise, there are changes in data patterns in the period before 2007, between 2007 and 2010, and after 2010 in the inflow and outflow data. This causes SSA can't optimally reconstruct trend pattern on inflow and outflow data, and it implies a less accurate prediction of the SSADNN model. Moreover, it also proves that the complexity of the model is not always directly proportional to the accuracy of prediction as the first result of the M3 competition Makridakis and Hibon (2000). In addition, more complex models generally need longer time in the estimation process, for example, DNN as machine learning models require a longer processing time than ARIMAX as statistical models, and this situation in line with the results of Makridakis et al. (2018a).

In addition, one of the main issues related to the accuracy of the DNN model is the determination of optimal inputs that follows the predictors and variable lags in the ARIMAX model. This is in line with some previous researches which shows that the main factor determining the prediction accuracy on the NN model is the corresponding input (Otok et al. 2011; Suhartono et al. 2018b). One of the main inputs in this study is dummy variable for calendar variation effect. It implies DNN could accurately handle calendar variation effect on inflow and outflow in Indonesia that have peak observations around this event.

\section{CONCLUSION}

Based on the results and discussion in the aforementioned section, some conclusions can be made from this study. First, the results of the simulation studies show that DNN yields a more accurate prediction than ARIMAX and hybrid SSA-DNN in time series data that contain a trend, seasonal, calendar variation, and nonlinear noise. Furthermore, the results of applied studies show that the best model for forecasting inflow and outflow in Indonesia is DNN. In general, the results show that DNN as a machine learning model provides a more accurate prediction than ARIMAX as a simpler statistical model, and this is in line with some previous research (Abdullah \& Nor-Muhammad 2018; Alzahrani et al. 2017; Bai et al. 20161; He 2017; Lago et al. 2018; Makridakis et al. 2018a; Makridakis \& Hibon 2000). The results also showed that DNN yields a more accurate prediction than hybrid SSA-DNN as a more complex model, and this is not in line with previous research (Makridakis et al. 2018a, 2018b; Makridakis \& Hibon 2000). Hence, DNN; with inputs such as ARIMAX model that involves dummy variables for trend, seasonal and calendar variations is the best model for inflow and outflow forecasting in Indonesia, both for short and long-term horizon.

In addition, the hybrid SSA-DNN gives relatively as accurate forecast as DNN in a simulation study for forecasting on data containing a trend, seasonal, calendar variation, and nonlinear noise. It indicates that choosing the appropriate model for each component of SSA is a major factor affecting the accuracy of the forecast. Thus, further research can be proposed to improve the accuracy of hybrid SSA-DNN through the use of an appropriate model for each SSA component, especially on data containing calendar variation, trend and seasonal patterns.

\section{ACKNOWLEDGEMENTS}

This research was supported by RISTEKDIKTI under Scheme B of World Class Professor (WCP) program, contract No. $123.32 / \mathrm{D} 2.3 / \mathrm{KP} / 2018$. The authors thank the General Director of DIKTI for funding and anonymous referees for their useful suggestions. Also, we would like to thank Universiti Teknologi Malaysia for Grant number 01M30.

\section{REFERENCES}

Abdullah, M.I. \& Nor-Muhammad, N.A. 2018. Prediction of colorectal cancer driver genes from Patients' Genome Data. Sains Malaysiana 47(12): 3095-3105.

Ahmad, I.S., Setiawan, S. \& Masun, N.H. 2015. Forecasting of monthly inflow and outflow currency using time series regression and ARIMAX: The Idul Fitri Effect. AIP Conference Proceedings 2015: 050002.

Alzahrani, A., Shamsi, P., Dagli, C. \& Ferdowsi, M. 2017. Solar irradiance forecasting using deep neural network. Procedia Computer Science 114: 304-313.

Bai, Y., Chen, Z., Xie, J. \& Li, C. 2016. Daily reservoir inflow forecasting using multiscale deep feature learning with hybrid models. Journal of Hydrology 532: 193-206. 
Bank Indonesia. 2011. Money Circulation. Gerai Info. pp. 1-8.

Bank Indonesia. 2018. Februari 17. Metadata SSKI. http://www.bi.go.id/id/statistik/metadata/SSKI/ Documents/12Metadata\%20Uang\%20Kartal\%20yang\%20 Diedarkan.pdf.

Bowerman, B.L. \& O'Connell, R.T. 1993. Forecasting and Time Series. Belmont: Wadsworth Publishing Company.

Busseti, E. 2012. Deep Learning for Time Series Modelling. Stanford: Stanford University.

Chen, Z. \& Yang, Y. 2004. Assessing forecast accuracy measures. Preprint Series pp. 1-26.

Crone, S.F. \& Kourentzes, N. 2009. Input-variable specification for neural network - An analysis of forecasting low and high time series frequency. International Joint Conference on Neural Network doi: 10.1109/IJCNN.2009.5179046.

Golyandina, N. \& Zhigljavsky, A. 2013. Singular Spectrum Analysis for Time Series. Heidelberg: Springer-Verlag Berlin.

Goodfellow, I., Bengio, Y. \& Courville, A. 2016. Deep Learning. Cambridge: MIT Press.

Gorr, W.L. 1994. Research prospective on neural network forecasting. International Journal of Forecasting 10(1): 1-4.

He, W. 2017. Load forecasting via deep neural networks. Procedia Computer Science 122: 308-314.

Kumar, U. \& Jain, V.K. 2010. Time series models (Grey-Markov, Grey Model with rolling mechanism and singular spectrum analysis) to forecast energy consumption in India. Energy 35: 1709-1716.

Lago, J., Ridder, F.D. \& Schutter, B.D. 2018. Forecasting spot electricity prices: Deep learning approach and empirical comparison of traditional algorithms. Applied Energy 221: 386-405.

Liu, H., Mi, X. \& Li, Y. 2018. Smart multi-step deep learning model for wind speed forecasting based on variational mode decomposition, singular spectrum analysis, LSTM network and ELM. Energy Conversion and Management 159: 54-64.

Makridakis, S. \& Hibon, M. 2000. The M3 competition: Results, conclusions, and inmplications. International Journal of Forecasting 16: 451-476.

Makridakis, S., Spiliotis, E. \& Assimakopoulos, V. 2018a Statistical and machine learning forecasting methods: Concerns and ways forward. PLOS ONE 13(3): e0194889.

Makridakis, S., Spiliotis, E. \& Assimakopoulos, V. 2018 b. The M4 competition: Results, findings, conclusions and way forward. International Journal of Forecasting. DOI: 10.1016/j.ijforecast.2018.06.001.

Otok, B.W., Suhartono, Ulama, B.S.S. \& Endharta, A.J. 2011. Design of experiment to optimize the architecture of wavelet neural network for forecasting the tourist arrivals in Indonesia. Communications in Computer and Information Science 253(3): 14-23.

Setiawan, Suhartono, Ahmad, I.S. \& Rahmawati, N.I. 2015. Configuring calendar variation based on time series regression method for forecasting of monthly currency inflow and outflow in Central Java. AIP Conference Proceedings 1691 2015: 050024.
Suhartono, Amalia, F.F., Saputri, P.D., Rahayu, S.P. \& Ulama, B.S.S. 2018a. Simulation study for determining the best architecture of multilayer perceptron for forecasting nonlinear seasonal time series. Journal of Physics: Conference Series 1028(1): 012214

Suhartono, Saputri, P.D., Prastyo, D.D. \& Rahayu, S.P. 2018 b. Hybrid quantile regression neural network model for forecasting currency inflow and outflow in Indonesia. Journal of Physics: Conference Series 1028(1): 012213.

Suhartono, Setyowati, E., Salehah, N.A., Lee, M.H., Rahayu, S.P. \& Ulama, B.S.S. 2017. A hybrid singular spectrum analysis and neural networks for forecasting inflow and outflow currency of Bank Indonesia. In. Soft Computing in Data Science, edited by Yap B., Mohamed A. \& Berry, M. Singapore: Springer Nature. pp. 3-18.

Suhartono. 2007. Feedforward neural network for time series forecasting. Yogyakarta: PhD Dissertation, Gadjah Mada University (Unpublished).

Vautard, R. \& Ghil, M. 1989. Singular spectrum analysis in nonlinear dynamics, with applications to paleoclimatic time series. Physica D: Nonlinear Phenomena 35: 395-424.

Yu, C., Li, Y. \& Zhang, M. 2017. Comparative study on three new hybrid models using Elman Neural Network and Empirical Mode Decomposition based technologies improved by Singular Spectrum Analysis for hour-ahead wind speed forecasting. Energy Conversion and Management 147: 76-85.

Zhang, X., Wang, J. \& Zhang, K. 2017. Short-term electric load forecasting based on singular spectrum analysis and support vector machine optimized by Cuckoo search algorithm. Electric Power Systems Research 146: 270-285.

Zubaidi, S.L., Dooley, J., Alkhaddar, R.M., Abdellatif, M., Al-Bugharbee, H., Ortega. \& Martorell, S.A. 2018. Novel approach for predicting monthly water demand by combining singular spectrum analysis with neural networks. Journal of Hydrology 561: 136-145.

Suhartono, Dimas Ewin Ashari, Dedy Dwi Prastyo \& Heri Kuswanto

Institut Teknologi Sepuluh Nopember

Surabaya-60111

Indonesia

Muhammad Hisyam Lee*

Universiti Teknologi Malaysia

81310 Johor Bahru, Johor Darul Takzim

Malaysia

*Corresponding author; email: mhl@utm.my

Received: 1 September 2018

Accepted: 29 May 2019 